\section{Long-term Follow-up of Glycemic and Neurological Outcomes in an International Series of Patients With Sulfonylurea-Treated ABCC8 Permanent Neonatal Diabetes}

Diabetes Care 2021;44:35-42 | https://doi.org/10.2337/dc20-1520
Pamela Bowman, ${ }^{1,2}$ Frances Mathews, ${ }^{1,2}$ Fabrizio Barbetti, ${ }^{3,4}$ Maggie H. Shepherd, ${ }^{1,2}$ Janine Sanchez, ${ }^{5}$ Barbara Piccini, ${ }^{6}$ Jacques Beltrand, $7,8,9$

Lisa R. Letourneau-Freiberg, ${ }^{10}$ Michel Polak, ${ }^{7,8,9}$ Siri Atma W. Greeley, ${ }^{10}$ Eamon Rawlins, ${ }^{2}$ Tarig Babiker, ${ }^{2}$ Nicholas J. Thomas, ${ }^{2}$ Elisa De Franco, ${ }^{2}$ Sian Ellard, ${ }^{2}$ Sarah E. Flanagan, ${ }^{2}$ and Andrew T. Hattersley, ${ }^{1,2}$ for the Neonatal Diabetes International Collaborative Group

\section{OBJECTIVE}

$A B C C 8$ mutations cause neonatal diabetes mellitus that can be transient (TNDM) or, less commonly, permanent (PNDM); $\sim 90 \%$ of individuals can be treated with oral sulfonylureas instead of insulin. Previous studies suggested that people with ABCC8PNDM require lower sulfonylurea doses and have milder neurological features than those with KCNJ11-PNDM. However, these studies were short-term and included combinations of $A B C C 8$-PNDM and $A B C C 8$-TNDM. We aimed to assess the long-term glycemic and neurological outcomes in sulfonylurea-treated $A B C C 8$-PNDM.

\section{RESEARCH DESIGN AND METHODS}

We studied all 24 individuals with ABCC8-PNDM diagnosed in the U.K., Italy, France, and U.S. known to transfer from insulin to sulfonylureas before May 2010. Data on glycemic control, sulfonylurea dose, adverse effects including hypoglycemia, and neurological features were analyzed using nonparametric statistical methods.

\section{RESULTS}

Long-term data were obtained for $\mathbf{2 1}$ of $\mathbf{2 4}$ individuals (median follow-up 10.0 [range 4.1-13.2] years). Eighteen of 21 remained on sulfonylureas without insulin at the most recent follow-up. Glycemic control improved on sulfonylureas (presulfonylurea vs. 1-year posttransfer $\mathrm{HbA}_{1 \mathrm{c}} \mathbf{7 . 2 \%}$ vs. $\left.5.7 \%, P=0.0004\right)$ and remained excellent long-term (1-year vs. 10 -year $\mathrm{HbA}_{1 \mathrm{c}} 5.7 \%$ vs. $6.5 \%, P=0.04$ ), $n=16$. Relatively high doses were used (1-year vs. 10 -year dose 0.37 vs. $0.25 \mathrm{mg} / \mathrm{kg} / \mathrm{day}$ glyburide, $P=0.50$ ) without any severe hypoglycemia. Neurological features were reported in $\mathbf{1 3}$ of $\mathbf{2 1}$ individuals; these improved following sulfonylurea transfer in 7 of 13 . The most common features were learning difficulties (52\%), developmental delay (48\%), and attention deficit hyperactivity disorder (38\%).

\section{CONCLUSIONS}

Sulfonylurea treatment of $A B C C 8$-PNDM results in excellent long-term glycemic control. Overt neurological features frequently occur and may improve with sulfonylureas, supporting early, rapid genetic testing to guide appropriate treatment and neurodevelopmental assessment.
${ }^{1}$ Exeter NIHR Clinical Research Facility, Royal Devon and Exeter NHS Foundation Trust, Exeter, U.K. ${ }^{2}$ Institute of Biomedical and Clinical Science, University of Exeter Medical School, Exeter, U.K. ${ }^{3}$ Department of Experimental Medicine, University of Rome Tor Vergata, Rome, Italy ${ }^{4}$ Bambino Gesù Children's Hospital, IRCCS, Rome, Italy

${ }^{5}$ Miller School of Medicine, University of Miami, Miami, FL

${ }^{6}$ Regional Center for Pediatric Diabetes, Meyer University Children's Hospital, Florence, Italy ${ }^{7}$ Service d'Endocrinologie, Gynécologie et Diabétologie Pédaitrique, APHP Centre, Université de Paris, Paris, France

${ }^{8}$ INSERM U1016, Paris, France

${ }^{9}$ Institut IMAGINE, Paris, France

${ }^{10}$ Kovler Diabetes Center, The University of Chicago, Chicago, IL

Corresponding author: Pamela Bowman, p.bowman@ exeter.ac.uk

Received 19 June 2020 and accepted 4 October 2020

Clinical trial reg. no. NCT02624830, clinicaltrials gov

This article contains supplementary material online at https://doi.org/10.2337/figshare.13053074.

(C) 2020 by the American Diabetes Association. Readers may use this article as long as the work is properly cited, the use is educational and not for profit, and the work is not altered. More information is available at https://www.diabetesjournals .org/content/license. 
The $A B C C 8$ gene encodes the SUR1 subunit of the pancreatic ATP-sensitive potassium ( $\mathrm{K}_{\text {ATP }}$ ) channel (1). SUR1 forms hetero-octameric complexes with Kir6.2, encoded by the KCNJ11 gene (2). Mutations in $\mathrm{K}_{\text {ATP }}$ channel genes are the most common cause of neonatal diabetes mellitus (NDM) in nonconsanguineous populations, with $\sim 15-20 \%$ as a result of $A B C C 8$ mutations and $\sim 25-30 \%$ as a result of KCNJ11 mutations (3). NDM typically occurs in the first 6 months of life and can be permanent (PNDM), where diabetes persists lifelong, or transient (TNDM), where there is a period of remission of diabetes after 6-12 months followed by relapse in adolescence or early adulthood (4). $A B C C 8$ mutations cause TNDM in $\sim 80 \%$ of cases and PNDM in $\sim 20 \%$; the opposite pattern is observed with KCNJ11 mutations, which most frequently result in PNDM (5).

$A B C C 8$ and KCNJ11 mutations cause NDM by preventing closure of pancreatic $\mathrm{K}_{\text {ATP }}$ channels in response to rising glucose $(6,7)$. This results in insulin deficiency, which historically has required treatment with replacement doses of insulin. However, in $\sim 90 \%$ of affected individuals, sulfonylurea treatment can bypass the genetic defect by binding SUR1 and closing pancreatic $\mathrm{K}_{\text {ATP }}$ channels, promoting secretion of endogenous insulin and allowing patients to stop insulin injections and achieve excellent glycemic control and better quality of life (8-10). Sulfonylureas are the optimum treatment for KCNJ11-PNDM long term; in patients who successfully transfer from insulin to sulfonylureas, metabolic control is maintained in $>90 \%$ for at least 10 years with no serious adverse effects, despite doses being $\sim 2-10$ times higher than those recommended in type 2 diabetes (11). Short-term studies have suggested that lower doses of sulfonylurea are required to treat $A B C C 8$-NDM compared with KCNJ11-NDM $(9,12)$. However, many studies have comprised individuals with $A B C C 8$-PNDM and with ABCC8-TNDM, which have different clinical courses and treatment requirements $(5,6,9)$. No study has assessed the long-term outcomes of sulfonylurea treatment specifically in ABCC8-PNDM.

$A B C C 8$ and $K C N J 11$ are both expressed in the brain as well as in the pancreas $(13,14)$; therefore, in addition to diabetes, central nervous system (CNS) features are observed in individuals with
$\mathrm{K}_{\text {ATP }}$ channel mutations. These vary from the severe DEND syndrome (developmental delay [DD], epilepsy, and NDM) to mild neuropsychological impairments detectable only on detailed neuropsychomotor testing $(5,15)$. In KCNJ11PNDM, there is some correlation between the position of the variant in the protein and the clinical features. In contrast, in ABCC8-PNDM, genotype-phenotype relationships appear less distinct (16). In around one-half of individuals with KCNJ11PNDM, sulfonylurea treatment results in partial improvement of the neurological features, which is believed to be due to the action of glyburide on $\mathrm{K}_{\mathrm{ATP}}$ channels in the brain $(11,17)$.

Observational studies have suggested that the CNS features are not as common and/or severe in individuals with $A B C C 8$ mutations $(5,6,18,19)$ compared with those with KCNJ11 mutations. However, as discussed above, previous research findings are based on cohorts containing both individuals with $A B C C 8$-PNDM and individuals with $A B C C 8$-TNDM. In addition, the majority of studies that have investigated the neurodevelopmental features associated with $\mathrm{K}_{\text {ATP }}$ channel mutations and the response of these features to sulfonylurea treatment focused on patients with KCNJ11-PNDM.

Research related to the CNS features in individuals with $A B C C 8-P N D M$ and the impact of long-term sulfonylurea treatment on both glycemic and neurological outcomes is crucial to establish and inform clinical guidelines for this specific subtype. The aim of this study was to assess the long-term glycemic and neurological response to sulfonylureas in an international cohort of patients with PNDM as a result of $A B C C 8$ mutations.

\section{RESEARCH DESIGN AND METHODS}

\section{Patient Cohort}

Patients with a molecular genetic diagnosis of PNDM as a result of mutations in the ABCC8 gene (NM_001287174.1) confirmed in laboratories in Exeter, Rome, Paris, and Chicago known to transfer to sulfonylureas before 30 April 2010 with no period of remission of their diabetes were eligible for inclusion in the study $(n=$ 24). Three patients were lost to follow-up in the 1st year after sulfonylurea transfer and were therefore excluded, leaving 21 patients with sufficient follow-up data ( $>4$ years) for further analyses.
The study was conducted in accordance with the Declaration of Helsinki as revised in 2000. Patient data were collected during routine clinical care or through research surveys and were anonymized for use in the study.

\section{Data Collection}

Data were collected from the clinical records of participating patients or through research surveys completed by the participant or their carers. Data on glycemic control, sulfonylurea dose, and hypoglycemia were collected before and after transfer from insulin to sulfonylureas and annually until the most recent clinic follow-up. Clinicians and participants were asked to report side effects or diabetes complications that occurred at any time point during the followup and, if so, to provide details about these.

Data on neurological features were collected before transfer from insulin to sulfonylureas and after transfer at the most recent follow-up. Clinicians or participants were specifically asked about the presence of $D D$, learning difficulties (LD), attention deficit hyperactivity disorder, epilepsy, sleep problems, muscle weakness, anxiety, autism, and spasticity as well as about other difficulties (11) and whether these features (if present) had improved on transfer to sulfonylureas.

\section{Statistical Analysis}

Data were analyzed with Stata 16.0 software using nonparametric statistical methods. Clinical characteristics of patients who remained on sulfonylureas alone were compared with those who required permanent reintroduction of insulin using the Mann-Whitney test for continuous data and two-sample test of proportions for categorical data. For those patients who remained on sulfonylureas alone for the duration of the follow-up, paired data on metabolic control $\left(\mathrm{HbA}_{1 \mathrm{c}}\right)$ and sulfonylurea dose were compared using the Wilcoxon signed rank test. For individuals with annual data available for $>50 \%$ of time points, longitudinal trends in $\mathrm{HbA}_{1 \mathrm{c}}$ and sulfonylurea dose were plotted. Missing data were imputed as previously described (11).

Individuals who required insulin therapy only transiently or who were prescribed any other oral antidiabetic medication at 
any point in the follow-up were classified in the sulfonylurea-only group. One individual (mutation, L1148R/R1380C) transferred from insulin to sulfonylureas twice at age 18 months (for 4 years) and again at age 26 years. His follow-up data relate to the second sulfonylurea transfer because no data were available after the first transfer 35 years ago.

For sulfonylureas other than glyburide, doses were converted to glyburide equivalent using percentage of maximum glibenclamide (glyburide) dose as per the British National Formulary (20). Data are presented as median (range) unless stated otherwise. For all analyses, $P<0.05$ was used to denote statistical significance.

Data and Resource Availability

The research data supporting this publication are provided within the manuscript and Supplementary Material.

\section{RESULTS}

\section{Clinical Characteristics}

Clinical characteristics of the patients included in the study are shown in Tables 1 and 2.

\section{Duration of Follow-up}

Median duration of follow-up was 10.0 (4.1-13.2) years, comprising a total of 205 patient-years.

\section{Sulfonylurea Efficacy}

At most recent follow-up, 18 of 21 (86\%) patients remained on sulfonylurea therapy without insulin. For all three individuals who had restarted insulin, clinicians reported problems with adherence with prescribed medication and/or periods of loss to clinic/hospital follow-up. Clinical characteristics were similar between the individuals who remained on sulfonylureas versus those who required reintroduction of insulin (Table 1).

\section{Type of Sulfonylurea Prescribed}

All patients who remained independent of insulin at most recent follow-up were prescribed glyburide for the duration of the study. One patient was prescribed glyburide at initial transfer from insulin and was switched to tolbutamide at day 45 posttransfer (21); this individual subsequently required reintroduction of insulin therapy, having stopped sulfonylurea treatment while lost to hospital follow-up.

\section{Metabolic Control and Sulfonylurea \\ Dose}

Paired data on pretransfer $\mathrm{HbA}_{1 \mathrm{c}}$ and $\mathrm{HbA}_{1 \mathrm{c}}$ and sulfonylurea dose at year 1 (median 0.97 years, range 0.27-1.76 years) and year 10 (9.8 years, 6.1-12.5 years) were available for 16 individuals. In these individuals, glycemic control improved on transfer to sulfonylurea (pretransfer vs. 1-year $\mathrm{HbA}_{1 \mathrm{c}}$ 7.2\% [5.3-9.5\%]

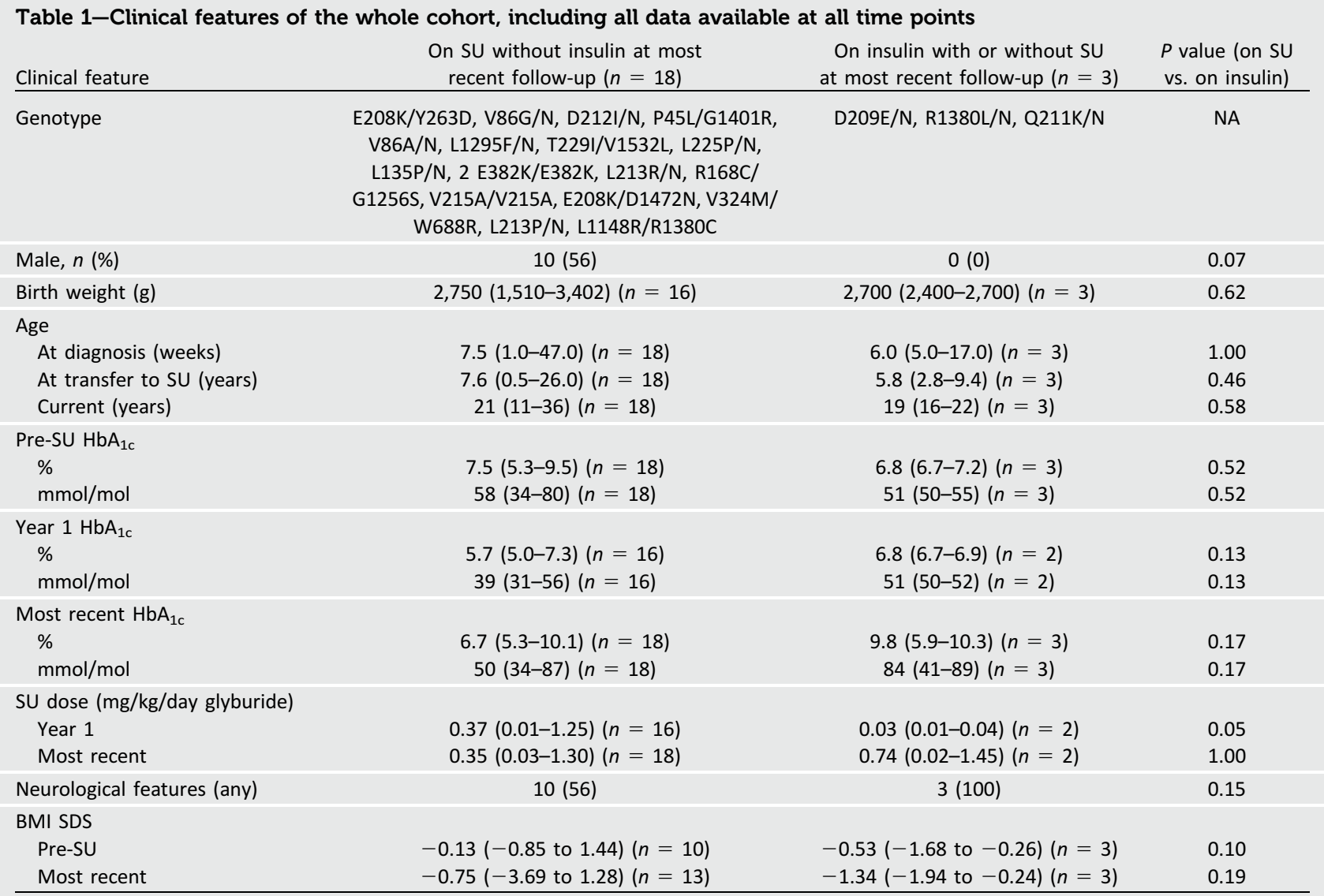

Data are median (range) unless otherwise indicated. Year 1 is median duration $0.97(0.27-1.76)$ years; data closest to 1 year were used. Most recent duration for $\mathrm{SU}$ dose and $\mathrm{HbA}_{1 \mathrm{c}}$ is median 10.0 (4.1-13.2) years. Most recent duration for $\mathrm{BMI}$ is 9.8 (4.6-13.2) years (most recent time point at which both height and weight data were available). The number of patients is different for each variable because of differences in amount of available data. Most recent SU dose is different from that reported in the RESULTs section because of paired values for SU dose and $\mathrm{HbA}_{1 \mathrm{c}}$ at all time points being unavailable for three individuals included in the table. NA, not applicable; SDS, SD score; SU, sulfonylurea. 
vs. $5.7 \%[5.0-7.3 \%][55(34-80)$ vs. $39(31-56) \mathrm{mmol} / \mathrm{mol}], P=0.0004)$ and remained excellent at long-term follow-up (1-year vs. 10-year $\mathrm{HbA}_{1 \mathrm{c}} 5.7 \%$ [5.0-7.3\%] vs. $6.5 \%[5.3-7.7 \%][39(31-56)$ vs. $48(34-$ 61) $\mathrm{mmol} / \mathrm{mol}], P=0.04$ ) (Fig. $1 A$ ). High doses of sulfonylurea were used in most individuals (1-year vs. 10-year dose 0.37 [0.01-1.25] vs. $0.25[0.03-1.30] \mathrm{mg} / \mathrm{kg} /$ day glyburide, $P=0.50$ ) (Fig. $1 B$ ). Only three individuals required doses under $0.1 \mathrm{mg} / \mathrm{kg} /$ day glyburide at most recent follow-up. In 11 individuals who had sufficient annual data available, there was a gradual reduction in median sulfonylurea dose per kilogram of body weight over time, despite relatively stable glycemic control (Supplementary Fig. 1).

\section{Side Effects}

Diarrhea was reported in two individuals. One individual was diagnosed with irritable bowel syndrome. The second individual, previously reported by Codner et al. (21), experienced transient diarrhea on glyburide; this stopped on switching to tolbutamide. No other adverse effects of sulfonylurea therapy were reported.

\section{Hypoglycemia}

There were no episodes of severe hypoglycemia, defined as losing consciousness or having seizures (22), reported over the course of the follow-up in patients treated with sulfonylurea alone. In one individual on glyburide treatment, an episode was reported whereby the blood glucose remained $<4.0 \mathrm{mmol} / \mathrm{L}$ even after treatment with fruit juice, and third-party assistance was required. Another individual switched treatment from glyburide to tolbutamide (see above) because of episodes of asymptomatic hypoglycemia on glyburide treatment; these settled on tolbutamide (21).

\section{Diabetes Complications}

Microvascular complications occurred in two individuals: One had microalbuminuria, and one had microalbuminuria (normotensive) and proliferative retinopathy requiring intravitreal injections and photocoagulation as well as mildly elevated LDL treated with a statin medication. These individuals transferred to sulfonylureas at age 10 years and 26 years, respectively (after a short period of sulfonylurea treatment as a child [see above]). There were no macrovascular complications reported over the period of follow-up.

\section{BMI}

In 10 individuals who remained independent of insulin and had paired height and weight data available, BMI remained normal (BMI SD score presulfonylurea treatment $-0.13[-0.85$ to 1.44] and at most recent follow-up on sulfonylureas -0.29 [ -0.99 to 0.94$]$, $P=0.23$ )

\section{CNS Features}

Thirteen of $21(62 \%)$ patients were reported to have CNS features before and after transfer to sulfonylureas (Fig. 2 and Supplementary Table 1). The most common features at most recent follow-up

Table 2-Clinical features of individuals with dominantly vs. recessively inherited variants in the $A B C C 8$ gene

\begin{tabular}{|c|c|c|c|}
\hline Clinical feature & Dominant heterozygous $(n=11)$ & $\begin{array}{l}\text { Recessive (compound heterozygous/ } \\
\text { homozygous) }(n=10)\end{array}$ & $\begin{array}{c}P \\
\text { value }\end{array}$ \\
\hline Genotype & $\begin{array}{c}\mathrm{D} 209 \mathrm{E} / \mathrm{N}, \mathrm{D} 212 \mathrm{I} / \mathrm{N}, \mathrm{L} 1295 \mathrm{~F} / \mathrm{N}, \mathrm{L} 135 \mathrm{P} / \mathrm{N}, \\
\mathrm{L} 213 \mathrm{P} / \mathrm{N}, \mathrm{L} 213 \mathrm{R} / \mathrm{N}, \mathrm{L} 225 \mathrm{P} / \mathrm{N}, \mathrm{Q} 211 \mathrm{~K} / \mathrm{N}, \\
\mathrm{R} 1380 \mathrm{~L} / \mathrm{N}, \mathrm{V} 86 \mathrm{G} / \mathrm{N}, \mathrm{V} 86 \mathrm{~A} / \mathrm{N}\end{array}$ & $\begin{array}{l}2 \text { E382K/E382K, E208K/D1472N, E208K/ } \\
\text { Y263D, L1148R/R1380C, P45L/G1401R, } \\
\text { R168C/G1256S, T229I/V1532L, V215A/ } \\
\text { V215A, V324M/W688R }\end{array}$ & NA \\
\hline Duration of follow-up (years) & $11.2(7.9-13.2)$ & $9.1(4.1-12.3)$ & 0.02 \\
\hline Male, $n(\%)$ & $4(36)$ & $6(60)$ & 0.27 \\
\hline Birth weight (g) & $2,700(2,100-3,065)(n=9)$ & $2,750(1,510-3,402)(n=10)$ & 0.76 \\
\hline Age & & & \\
\hline $\begin{array}{l}\text { At diagnosis (weeks) } \\
\text { At transfer to SU (years) } \\
\text { Current (years) }\end{array}$ & $\begin{array}{c}6(2-17)(n=11) \\
5.8(1.9-12.0)(n=11) \\
19(15-23)(n=11)\end{array}$ & $\begin{array}{c}11(1-47)(n=10) \\
10.3(0.5-26.0)(n=10) \\
22.5(11-36)(n=10)\end{array}$ & $\begin{array}{l}0.48 \\
0.12 \\
0.08\end{array}$ \\
\hline $\begin{array}{l}\text { Pre-SU } \mathrm{HbA}_{1 \mathrm{c}} \\
\quad \% \\
\quad \mathrm{mmol} / \mathrm{mol}\end{array}$ & $\begin{array}{l}6.7(5.3-7.9)(n=11) \\
50(34-63)(n=11)\end{array}$ & $\begin{array}{l}8.1(5.8-9.5)(n=10) \\
65(40-80)(n=10)\end{array}$ & $\begin{array}{l}0.001 \\
0.001\end{array}$ \\
\hline $\begin{array}{l}\text { Year } 1 \mathrm{HbA}_{1 \mathrm{c}} \\
\% \\
\mathrm{mmol} / \mathrm{mol}\end{array}$ & $\begin{array}{l}6.0(5.0-6.9)(n=10) \\
42(31-52)(n=10)\end{array}$ & $\begin{array}{l}5.7(5.0-7.3)(n=8) \\
39(31-56)(n=8)\end{array}$ & $\begin{array}{l}0.92 \\
0.92\end{array}$ \\
\hline $\begin{array}{l}\text { Most recent } \mathrm{HbA}_{1 \mathrm{c}} \\
\% \\
\mathrm{mmol} / \mathrm{mol}\end{array}$ & $\begin{array}{l}7.0(5.3-10.3)(n=11) \\
53(34-89)(n=11)\end{array}$ & $\begin{array}{l}6.3(5.3-10.1)(n=10) \\
45(34-87)(n=10)\end{array}$ & $\begin{array}{l}0.32 \\
0.32\end{array}$ \\
\hline $\begin{array}{l}\text { SU dose }(\mathrm{mg} / \mathrm{kg} / \text { day glyburide) } \\
\text { Year } 1 \\
\text { Most recent }\end{array}$ & $\begin{array}{l}0.09(0.01-1.25)(n=10) \\
0.36(0.02-1.45)(n=10)\end{array}$ & $\begin{array}{l}0.50(0.17-1.11)(n=8) \\
0.35(0.10-1.30)(n=10)\end{array}$ & $\begin{array}{l}0.08 \\
0.67\end{array}$ \\
\hline On insulin at recent follow-up, $n$ (\%) & $3(27)$ & $0(0)$ & 0.08 \\
\hline $\begin{array}{l}\text { With neurological features any at most recent } \\
\text { visit, } n(\%)\end{array}$ & $7(64)$ & $6(60)$ & 0.85 \\
\hline
\end{tabular}

Data are median (range) unless otherwise indicated. The number of patients is different for each variable because of differences in the amount of available data. NA, not applicable; SU, sulfonylurea. 

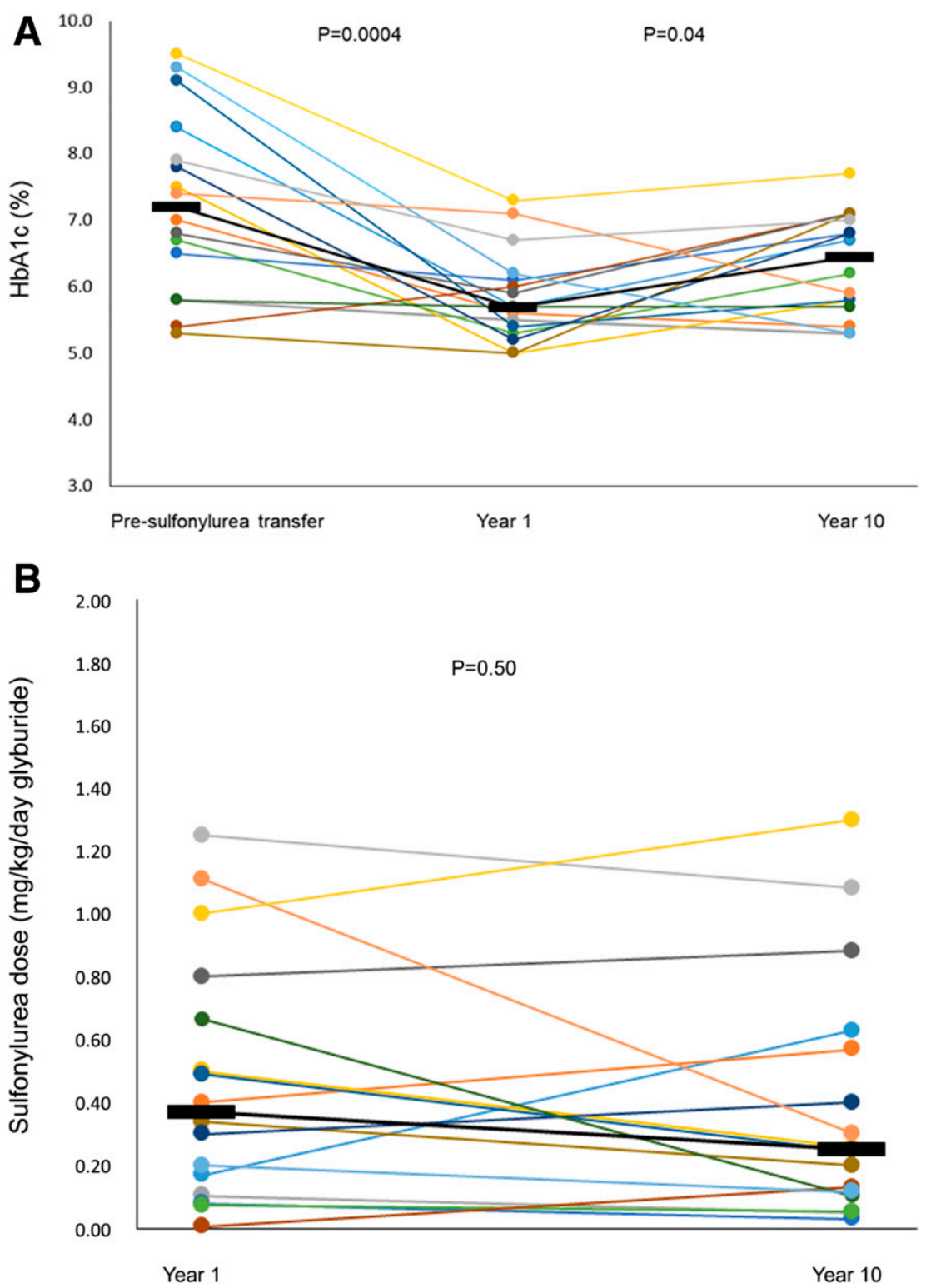

Figure 1-A: $\mathrm{HbA}_{1 \mathrm{c}}$ pre-sulfonylurea transfer at year 1 and at most recent follow-up in 16 patients with data available at all three time points. Circles represent individuals, and black horizontal lines represent group medians. $B$ : Sulfonylurea dose at year 1 and at most recent follow-up in 16 patients included in panel $A$. Circles represent individuals, and black horizontal lines represent group medians.

were DD in $48 \%$, LD in 52\%, and attention deficit hyperactivity disorder in $38 \%$. Comorbidity was common: 11 individuals had three or more specific CNS features together. In five individuals, seizures were or may have been a result of factors other than the genetic mutation (Supplementary Table 2).

In 7 of 13 (54\%) patients, there was some improvement $(n=5)$ or complete resolution ( $n=2$ ) noted in neurological features on starting sulfonylureas (Fig. 2 and Supplementary Table 1). In the two patients whose neurological features completely resolved, both had
DD pretransfer (with LD in one) but subsequently attained a developmental level expected for their age.

All three patients who required reintroduction of insulin treatment had neurological features (Table 1); there was improvement in the electroencephalogram background in one of these patients following initial transfer from insulin onto sulfonylureas. Age at transfer to sulfonylureas was similar in patients with and without neurological features at most recent follow-up (6.6 [0.5-18.2] vs. $8.4[0.9-26.0]$ years, $P=$ $0.53)$.

\section{CONCLUSIONS}

In summary, in our 10-year study of 21 individuals with sulfonylurea-treated ABCC8-PNDM, 86\% remained independent of insulin at their most recent follow-up. Furthermore, glycemic control was maintained on relatively high doses of sulfonylureas, without any reports of severe hypoglycemia or side effects. A large proportion of the cohort (62\%) had overt neurological features both before sulfonylurea transfer and at most recent follow-up, and comorbidity was common. There was partial improvement in some CNS features in just over one-half of individuals following transfer to sulfonylurea therapy.

The excellent long-term outcomes in sulfonylurea-treated $A B C C 8$-PNDM are similar to those observed in KCNJ11PNDM (11) (Supplementary Table 3). Our data do not support the suggestion from previous studies that lower doses of sulfonylurea may be required in people with $A B B C 8$ mutations compared with those with KCNJ11 mutations (9). This may be due to, at least in part, the inclusion of patients with $A B C C 8-T N D M$ and $A B C C 8$-PNDM in earlier cohort studies (9) and a lower sulfonylurea dose requirement in the patients with TNDM (23). In this study, behavioral and/or social factors are likely to explain the deterioration in glycemic control in the three individuals with $A B C C 8$-PNDM who required reintroduction of insulin.

We have shown that overt CNS features in ABCC8-PNDM occur with relatively high frequency and that comorbidity is common, in contrast with previous studies that included cohorts of patients with $A B C C 8$-TNDM and ABCC8-PNDM $(5,6,9)$. Indeed, the frequency and nature of CNS features in ABCC8-PNDM is similar to that observed in KCNJ11-PNDM (11) (Supplementary Table 3), with the exception of autism, which has been more frequently reported in KCNJ11-PNDM $(11,24,25)$.

The partial improvement in neurological features in 7 of 13 individuals on transferring to sulfonylureas is consistent with previous cases and suggests that the drugs may improve neurological function in some patients with ABCC8-PNDM, although a randomized controlled trial would be required to prove this definitively. It has been suggested 


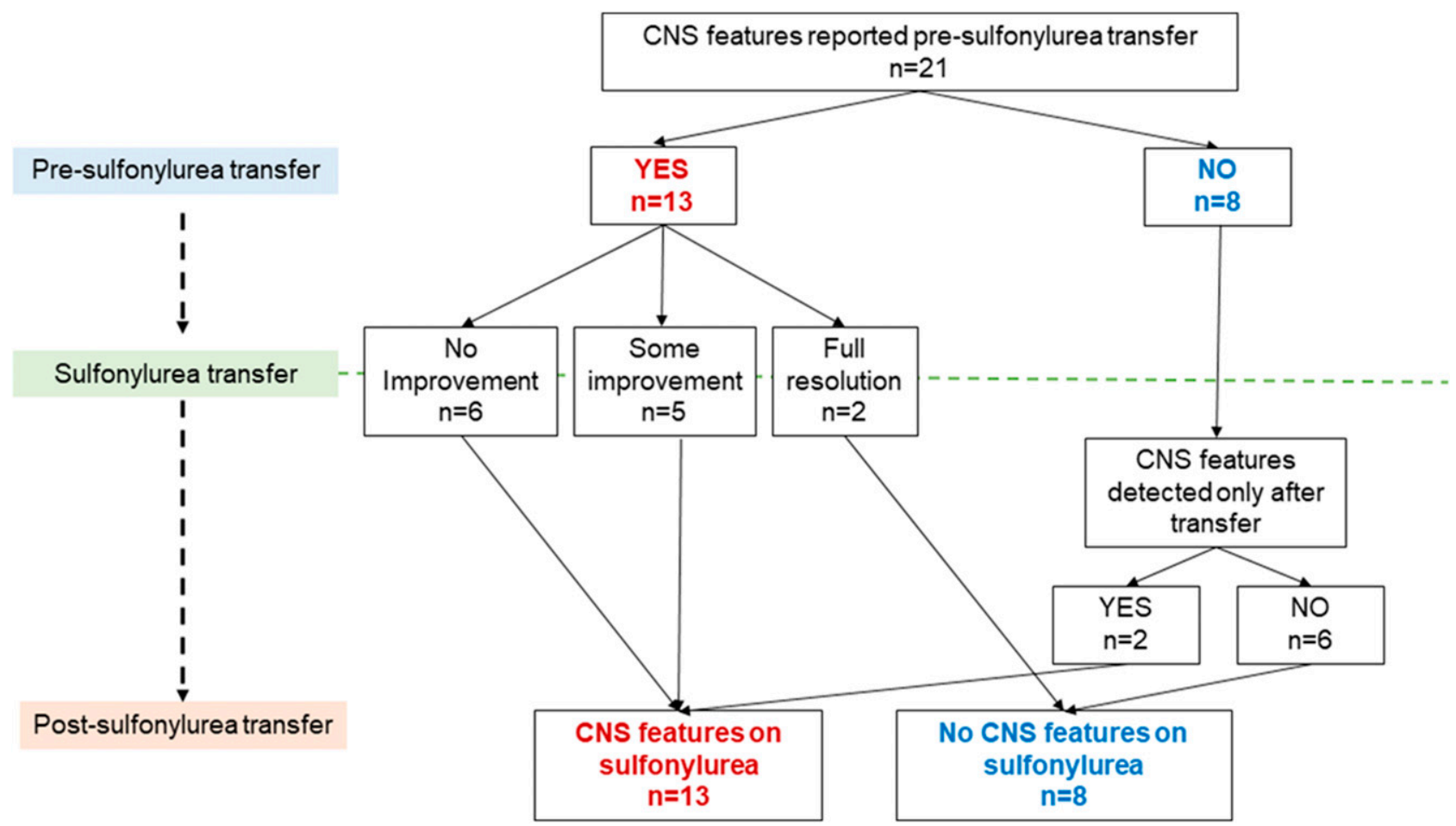

Figure 2-Number of patients with ABCC8-PNDM with neurological features relative to sulfonylurea transfer.

that the improvement in neurological features is greater the earlier sulfonyl ureas are started $(17,26)$, reflecting greater neuroplasticity at a younger age with a so-called sensitive period occurring within the first 6 months of life (27). In our cohort, only two patients transferred under the age of 1 year, and none transferred under the age of 6 months; therefore, this crucial sensitive period for the action of sulfonylureas in the brain may have been missed. Studies in rats have suggested that glyburide is actively transported out of the brain (28); this may make it difficult to achieve therapeutic concentrations of the drug in the cerebrospinal fluid. As a result, recommended doses of glyburide in patients with $\mathrm{K}_{\mathrm{ATP}}$ channelrelated PNDM and severe neurological features are higher (at least $\sim 1 \mathrm{mg} / \mathrm{kg}$ / day) (29). Of those individuals who remained independent of insulin in our cohort, only two were on a dose this high at their most recent follow-up. Furthermore, there was a tendency for glyburide doses to fall over time, which may reflect lack of adjustment of total daily doses according to increases in body weight as children grow. This may also explain the slightly higher $\mathrm{HbA}_{1 \mathrm{c}}$ at the most recent follow-up when compared with year 1 .
These factors emphasize the need for early genetic testing and identification of all patients with $A B C C 8$-PNDM. Prompt genetic diagnosis facilitates early transfer to sulfonylureas as well as systematic screening of all affected individuals for neurodevelopmental features at diagnosis and follow-up and provision of appropriate support. Clinicians should consider higher doses of sulfonylureas if neurological features are present. They should also regularly adjust total daily dose to maintain the same dose per kilogram of body weight over time, thereby optimizing treatment for both glycemia and neurological features.

Variable modes of inheritance are observed in our cohort; there is a mixture of dominant heterozygous $A B C C 8$ mutations $(n=11)$ as well as compound heterozygous ( $n=7$ ) and homozygous variants $(n=3)$, in keeping with previous studies (30). This has implications for genetic counseling in relation to recurrence risk and carrier status in future offspring, which will be different for dominant versus recessive inheritance. In this study, there were no differences in long-term outcomes between individuals with dominant heterozygous versus recessive (homozygous and compound heterozygous) mutations (Table 2). However, our study was not designed to address this question, and research in larger cohorts will be required to investigate the impact of mode of inheritance on clinical outcomes in ABCC8-PNDM. An additional limitation is the wide range of specific genetic variants included, which prevents the identification of strong genotype-phenotype relationships.

Finally, neurological features were not screened for systematically through repeated assessments in one center over the course of the follow-up, and comprehensive neuropsychological testing was not done as part of this study. Therefore, there is likely to be variable ascertainment and/or reporting of CNS features on the basis of what was recorded in the clinical notes. This might result in an underestimation of the extent of neurological involvement in affected individuals. It is not possible to fully distinguish the relative contributions of mutant $K_{\text {ATP }}$ channels in the brain and other factors from the neurological features reported (Supplementary Table 2). It is likely that in at least some individuals, the neurological features will be due to a combination of different etiologies. Despite these limitations, this study is the first to assess the long-term treatment response and CNS features in an international cohort of patients with $A B C C 8$-PNDM. Further research in larger 
cohorts of individuals with $A B C C 8$ mutations will be required to investigate in more detail the CNS phenotype, genotype-phenotype relationships, and factors influencing the glycemic response to sulfonylureas (e.g., specific physiological states such as puberty and pregnancy).

In conclusion, we have shown for the first time that sulfonylurea therapy is effective and safe long term for people with PNDM as a result of $A B C C 8$ mutations, with excellent glycemic control maintained over 10 years without severe hypoglycemia or side effects, despite relatively high doses in most patients. Importantly, affected individuals frequently have multiple overt CNS features, which, in some, may partly improve with sulfonylureas. Rapid genetic diagnosis is crucial to facilitate early initiation of precision therapy with sulfonylureas in $A B C C 8$ PNDM and to enable prompt identification of neurodevelopmental features and provision of appropriate support for affected families.

Acknowledgments. The authors offer many thanks to the clinicians in the Neonatal Diabetes International Collaboration (Supplementary Material) for contributions to data collection and to the Exeter NIHR Clinical Research Facility for supporting the study. The authors also thank Prof. Tamsin Ford (University of Cambridge, Cambridge, U.K.) for academic supervision of the first author during the study. Finally, the authors thank Dr. John Dennis (University of Exeter) for advice on statistical methods.

Funding. P.B. has a Sir George Alberti Clinical Research Training Fellowship funded by Diabetes UK (grant number 16/0005407). M.H.S. is a National Institute for Health Research (NIHR) Senior Nurse and Midwife Research Leader (NIHR4-SNMRL058) and is also supported by the Exeter NIHR Clinical Research Facility at the University of Exeter. N.J.T. is funded by a Wellcome Trust-funded GW4 PhD. E.D.F. has an RD Lawrence Fellowship funded by Diabetes UK (19/005971). S.E.F. has a Sir Henry Dale Fellowship jointly funded by the Wellcome Trust and the Royal Society (grant number 105636/Z/14/Z). A.T.H. is supported by a Wellcome Trust Senior Investigator award (grant number 098395/Z/12/ Z). The University of Chicago Monogenic Diabetes Registry is supported by grants from the National Institute of Diabetes and Digestive and Kidney Diseases (R01-DK-104942 and P30-DK-020595).

The views expressed in this article are those of the authors and not necessarily those of the NIHR or the Department of Health and Social Care.

Duality of Interest. No potential conflicts of interest relevant to this article were reported. Author Contributions. P.B. wrote the manuscript and all authors reviewed, critically revised, and approved the manuscript for submission. P.B., F.M., F.B., M.H.S., J.S., B.P., J.B., L.R.L.-F.,
M.P., S.A.W.G., E.R., T.B., N.J.T., E.D.F., S.E., S.E.F., and A.T.H. were involved in data collection. P.B., F.M., E.R., S.E.F., and A.T.H. were involved in data cleaning, analysis, and interpretation. P.B., F.B., J.B., M.P., T.B., N.J.T., and A.T.H. were involved in the study design and protocol development. E.D.F. was involved in the genetic analysis. P.B. is the guarantor of this work and, as such, had full access to all the data in the study and takes responsibility for the integrity of the data and the accuracy of the data analysis.

Prior Presentation. Parts of this study were accepted for presentation in abstract and poster form at Diabetes UK 2020, which was cancelled as a result of coronavirus disease 2019 .

\section{References}

1. Aguilar-Bryan L, Nichols CG, Wechsler SW, et al. Cloning of the beta cell high-affinity sulfonylurea receptor: a regulator of insulin secretion. Science 1995;268:423-426

2. Clement JP IV, Kunjilwar K, Gonzalez G, et al. Association and stoichiometry of K(ATP) channel subunits. Neuron 1997;18:827-838

3. De Franco E, Flanagan SE, Houghton JA, et al. The effect of early, comprehensive genomic testing on clinical care in neonatal diabetes: an international cohort study. Lancet 2015; 386:957-963

4. Flanagan SE, Patch AM, Mackay DJ, et al. Mutations in ATP-sensitive $\mathrm{K}+$ channel genes cause transient neonatal diabetes and permanent diabetes in childhood or adulthood. Diabetes 2007;56:1930-1937

5. Busiah K, Drunat S, Vaivre-Douret L, et al.; French NDM study group. Neuropsychological dysfunction and developmental defects associated with genetic changes in infants with neonatal diabetes mellitus: a prospective cohort study [corrected]. Lancet Diabetes Endocrinol 2013;1:199-207

6. Babenko AP, Polak M, Cavé $\mathrm{H}$, et al. Activating mutations in the $A B C C 8$ gene in neonatal diabetes mellitus. N Engl J Med 2006;355:456-466 7. Gloyn AL, Pearson ER, Antcliff JF, et al. ACtivating mutations in the gene encoding the ATPsensitive potassium-channel subunit Kir6.2 and permanent neonatal diabetes. $\mathrm{N}$ Engl J Med 2004:350:1838-1849

8. Pearson ER, Flechtner I, Njølstad PR, et al.; Neonatal Diabetes International Collaborative Group. Switching from insulin to oral sulfonylureas in patients with diabetes due to Kir6.2 mutations. N Engl J Med 2006;355:467-477

9. Rafiq M, Flanagan SE, Patch AM, Shields BM, Ellard S, Hattersley AT; Neonatal Diabetes International Collaborative Group. Effective treatment with oral sulfonylureas in patients with diabetes due to sulfonylurea receptor 1 (SUR1) mutations. Diabetes Care 2008:31:204-209

10. Shepherd M. Transforming lives: transferring patients with neonatal diabetes from insulin to sulphonylureas. Eur Diabetes Nurs 2006;3: 137-142

11. Bowman P, Sulen A, Barbetti F, et al.; Neonatal Diabetes International Collaborative Group. Effectiveness and safety of long-term treatment with sulfonylureas in patients with neonatal diabetes due to KCNJ11 mutations: an international cohort study [published correction appears in Lancet Diabetes Endocrinol 2018;6: e17]. Lancet Diabetes Endocrinol 2018;6:637-646
12. Proks P. Neonatal diabetes caused by activating mutations in the sulphonylurea receptor. Diabetes Metab J 2013;37:157-164

13. Ashcroft FM. ATP-sensitive potassium channelopathies: focus on insulin secretion. J Clin Invest 2005;115:2047-2058

14. Sakura H, Ammälä C, Smith PA, Gribble FM, Ashcroft FM. Cloning and functional expression of the cDNA encoding a novel ATP-sensitive potassium channel subunit expressed in pancreatic beta-cells, brain, heart and skeletal muscle. FEBS Lett 1995;377:338-344

15. Gloyn AL, Diatloff-Zito C, Edghill EL, et al. KCNJ11 activating mutations are associated with developmental delay, epilepsy and neonatal diabetes syndrome and other neurological features. Eur J Hum Genet 2006;14:824-830

16. Edghill EL, Flanagan SE, Ellard S. Permanent neonatal diabetes due to activating mutations in ABCC8 and KCNJ11. Rev Endocr Metab Disord 2010;11:193-198

17. Beltrand J, Elie C, Busiah K, et al.; GlidKir Study Group. Sulfonylurea therapy benefits neurological and psychomotor functions in patients with neonatal diabetes owing to potassium channel mutations. Diabetes Care 2015;38:2033-2041

18. Hashimoto $Y$, Dateki $S$, Hirose $M$, et al. Molecular and clinical features of $\mathrm{K}_{\text {ATP }}$-channel neonatal diabetes mellitus in Japan. Pediatr Diabetes 2017;18:532-539

19. Aittoniemi J, Fotinou $\mathrm{C}$, Craig TJ, de Wet $\mathrm{H}$, Proks P, Ashcroft FM. Review. SUR1: a unique ATP-binding cassette protein that functions as an ion channel regulator. Philos Trans R Soc Lond B Biol Sci 2009;364:257-267

20. Joint Formulary Committee. British National Formulary. London, BMJ Group and Pharmaceutical Press. Accessed 1 April 2020. Available from https://www.medicinescomplete.com

21. Codner E, Flanagan SE, Ugarte $F$, et al. Sulfonylurea treatment in young children with neonatal diabetes: dealing with hyperglycemia, hypoglycemia, and sick days. Diabetes Care 2007; 30:e28-e29

22. Ly TT, Maahs DM, Rewers A, Dunger $D$, Oduwole A, Jones TW; International Society for Pediatric and Adolescent Diabetes. ISPAD Clinical Practice Consensus Guidelines 2014. Assessment and management of hypoglycemia in children and adolescents with diabetes. Pediatr Diabetes 2014;15(Suppl. 20):180-192

23. Diabetes Genes, Exeter. Sulphonylurea transfer in patients with $\mathrm{KCNJ} 11$ and $\mathrm{ABCC} 8$ mutationsTNDM. Accessed 1 May 2020. Available at https:// www.diabetesgenes.org/about-neonatal-diabetes/ transferring-patients-who-have-a-mutation-inkcnj11-or-abcc8

24. Bowman $P$, Broadbridge $E$, Knight $B A$, et al. Psychiatric morbidity in children with KCNJ11 neonatal diabetes. Diabet Med 2016;33:1387-1391 25. Svalastoga P, Sulen $\AA$, Fehn JR, et al. Intellectual disability in $K_{\text {ATP }}$ channel neonatal diabetes. Diabetes Care 2020;43:526-533 26. Shah RP, Spruyt K, Kragie BC, Greeley SA, Msall ME. Visuomotor performance in KCNJ11related neonatal diabetes is impaired in children with DEND-associated mutations and may be improved by early treatment with sulfonylureas. Diabetes Care 2012;35:2086-2088

27. Zeanah CH, Gunnar MR, McCall RB, Kreppner JM, Fox NA. Sensitive periods. Monogr Soc Res Child Dev 2011;76:147-162 
28. Lahmann C, Kramer HB, Ashcroft FM. Systemic administration of glibenclamide fails to achieve therapeutic levels in the brain and cerebrospinal fluid of rodents [published correction appears in PLoS One 2019;14:e0215989]. PLoS One 2015;10:e0134476
29. Diabetes Genes, Exeter. Effects of sulphonylurea on the brain. Accessed 1 May 2020. Available at https://www.diabetesgenes.org/aboutneonatal-diabetes/effects-of-sulphonylurea-onthe-brain
30. Ellard S, Flanagan SE, Girard CA, et al. Permanent neonatal diabetes caused by dominant, recessive, or compound heterozygous SUR1 mutations with opposite functional effects. Am J Hum Genet 2007;81:375-382 